\title{
Research on Teaching Innovation of College English in the Model of Mobile Fragmentation Learning
}

\author{
Dan $\mathrm{Li}^{1, \mathrm{a}}$ \\ ${ }^{1}$ College of Post and Telecommunication, Wuhan Institute of Technology, Wuhan, 430073, China \\ ${ }^{a}$ email
}

Keywords: College English, Teaching innovation, Mobile fragmentation learning

\begin{abstract}
With the rapid development of information technology, college English teaching is in line with the development of the times. In this paper, the main features of mobile fragmentation learning are analyzed. Based on these characteristics, this paper gives some directions of teaching innovation of college English, including the innovation of teaching tools, teaching interaction and teaching evaluation, to provide some references for the relative researchers.
\end{abstract}

\section{Introduction}

The concept of mobile fragmentation learning includes two aspects of meaning. On the one hand refers to the discreteness of the big data era of new media convenience and huge information content so that learners acquire knowledge fragmentation; on the other hand, it refers to the learners' use of spare time of continuous learning, which leads to the acquisition of knowledge fragmentation. Compared with the traditional classroom learning, the knowledge acquired by the above two methods is discrete, fragmentary, and lacks the overall knowledge structure. Compared with the traditional learning mode, fragmentation learning has the characteristics of high flexibility, strong pertinence and high absorption rate. The fragmentation of learning breaks the limitation of time and space of traditional learning, learners can be based on individual circumstances to choose the appropriate time for learning, but also can according to their own learning level or different purpose, flexible selection of learning content and progress. In addition, the learning content is divided into fragments, because the single pieces of learning take shorter time to maintain effective learner's attention spans, not tired, tired or not a physical or mental feeling, thus ensuring learners keen interest in learning, improve the learning effect. However, we have to admit that there are some shortcomings in the fragmented learning. Due to the fragmented learning time and segmentation of learning content, fragmented learning lack of coherence and traditional learning system, is not conducive to the learners form the overall and profound thinking, so as to form a complete and has personal knowledge system depth. Therefore, in the new context, how to improve the efficiency of college English teaching by using the advantages of this kind of learning mode, which is worthy of teachers' attention.

\section{Connotation of Mobile Fragmentation Learning of College English}

Fragmentation of Learning Time. Fragmentation is the integrity of the effective separation. The main purpose is to improve students' learning ability. College English learning is more suitable for scattered time to learn. English word learning is more suitable for scattered time learning. Study of the fragmentation of time to break the traditional teaching of English learning time limit, students can help the network platform at any place, any time for English learning, such as in the rest of the train, bus. That is to say, the learning time of students is more flexible, which is helpful to enhance the enthusiasm of students' study. Fragmented learning is the main way to learn in the future, especially the wide application of mobile communication equipment, which provides the possibility for the fragmentation study of English. In the traditional learning mode, college students often spend time in 
the library or classroom to read a book or an article to obtain knowledge and information. In the traditional learning, although the learning materials are relatively independent of each part, but the whole logic associated with longer length, the knowledge and information acquired by college students is relatively complete. Traditional learning methods can be called holistic learning. In contrast, the mobile Internet era of college students learning patterns show fragmented learning. In today's era, the pace of life of college students is significantly accelerated, it is difficult to draw a piece of time to learn books or articles. Its learning time is often waiting for the car, ride, recess, bedtime and other fragmented time, ranging from a few minutes to dozens of minutes, and often interrupted by other things. In the mobile internet environment, learning materials are also fragmented form. Under the mobile Internet environment, fragmented learning time makes the contemporary college students' English learning present fragmented form.

Fragmentation of Learning Space. Students with fragmented learning can do flexible learning in space. The students can learn English at any time, no limit of time and space, with the aid of the network platform, teachers and students can communicate, solve the students to ask questions, to stimulate students' interest in learning has certain research significance. The era of big data fragmentation learning has the characteristics of mobile learning, is based on the mobile communication technology, wireless network technology and mobile terminal equipment in a mobile environment of learning, learning is the extension and expansion in terms of time and space. With the advent. The rapid development of communication technology, its application to the teaching reform, improve the effect of teaching reform, teaching reform to provide technical support. The wide application of mobile Internet in college students makes the reading of college students change from fixed reading to jump reading. In the traditional mode of reading, college students hold books carefully, and their reading materials are relatively fixed. College students subject cannot jump in different books, is a fixed reading. Using the computer to browse the web belongs to jump reading. The use of hyperlinks makes the reading of college students no longer fixed in a book or an article, but continue to jump in the web pages. When browsing the web, there are dozens of hyperlinks in each page, just a little bit, you can change the content of the reading. In the mobile Internet environment in the reading mode, the browser's multi label mode makes the realization of the jump reading on the computer more convenient. Smart phones, micro-blog, WeChat browser is also a jump reading. In the smart phone, click on the head of a blogger micro-blog can enter its micro-blog page, click on the public account in the circle of friends of WeChat can enter the public account page. With the development of network technology and the upgrading of smart phones, micro-blog, WeChat, including pictures, audio, video and other interesting, attractive and strong reading materials, jump reading more common.

Fragmentation of Learning Content. English knowledge is very flexible, especially in the era of 4G. With the rapid development of network communication today, students can learn English through micro lessons, lessons and so on. It has a certain application value for the study of English words, and now it is the main way for students to learn English with the help of the network platform. The students by the means of science and technology, to learn knowledge of the integration of organic debris, applied science, better able to complete the task of learning, to enhance students' learning ability, and improve students' autonomous learning ability, improve the ability of innovation. In the traditional English learning mode, College English learners often fine style of English learning, to read a book or article carefully, thinking of its logic structure and internal details, in the key points to note and comment. Of course, the traditional English language learning also has the possibility to get type of learning English, because English learning materials are relatively fixed, when students browse to the interested section, still use the fine type of English learning, thinking and comments. In the mobile Internet environment to learn English, because a page is extremely huge, hyperlinks are among the college students, to find the hyperlink most attractive, often by browsing English learning methods, according to the interest to select hyperlink click on English learning. After clicking on the contents of the rough scan, the page again selects the most attractive hyperlink, continue to click browse, so reciprocating. 


\section{Teaching Innovation of College English in the Model of Mobile Fragmentation Learning}

Innovate Teaching Tools. In the process of mobile learning, teachers should be based on the Internet in English resources, targeted to establish English mobile learning platform currently in the network, although there are a lot of English learning websites have launched mobile learning mobile phone sector but due to complicated operation, download mobile phone has increased the difficulty of the operation, if the students to download to learn it is difficult to grasp learning direction. In the mobile fragmentation learning, not to copy the contents of the English teaching materials to the mobile device, but the integration of teaching materials, processing. Teachers in the production of Mobile English learning resources, to be combined with the characteristics of mobile devices and the size of the student, the content in accordance with the teaching contents, outstanding English knowledge of relevant knowledge, and reasonable planning schedule. At the same time, teachers in the production process and the associated game music, the use of English learning resources in the form of a variety of forms to improve students' interest in learning. In addition, it can also establish the relevant micro learning resource library to achieve the purpose of optimizing the resource sharing. Teachers in the use of mobile micro teaching English, can be used with the university English four levels of listening ability is made into text and audio playback software, students in the mobile phone or computer to install this software can be used to play online answer, you can also view the related analysis. Teachers in making listening software process, according to different learning characteristics the students increase the difficulty of hearing at the same time, after the completion of the students' dictation results uploaded to the site, so that teachers understand the dynamic of students learning English, so as to carry out the next phase of the adjustment of listening teaching.

Innovate Teaching Interaction. With the rapid development of Internet information technology, mobile devices, such as mobile phones, not only bring convenience to students' learning life, but also bring some impact to the traditional English teaching mode to a certain extent. Therefore, teachers should change the teaching concept and teaching methods. The teacher according to the personality characteristics of the contemporary students and on mobile devices of love to design some related English learning software, with fresh teaching methods, learning content to students through mobile software delivery, let students acquire knowledge learning in the course of entertainment, the effect of edutainment. For teachers, we should constantly improve and reform the English teaching model. In the process of English classroom teaching, we should combine the Internet technology to create different teaching scenarios, and use the interesting teaching mode to meet the needs of the students, so as to improve the quality of English teaching. Due to the traditional college English learning, pay attention to the overall grasp of the time, often ignore the fragmented time, often lead to less effective. At this point, some English learning websites can play a better role in adjusting. As long as a registered account, the site will be on time every day to send the user's mailbox in English video, this time not exceeding two minutes, and can guarantee the quality of general vocabulary learners to understand learning materials is to improve the plight of University scattered time English learning tool. In College English teaching, teachers can use the class a few minutes before the students after class English test video learning content, through stories, jokes, singing songs such as English students love the way, to stimulate their learning motivation, cultivate a good habit of learning.

Innovate Teaching Evaluation. The incentive mechanism of College English learning is not perfect. Teachers should change the assessment model to enhance the practicality of College English teaching. English learning is a long-term investment and stable work enthusiasm, but in the traditional mode, the frame line teaching is difficult to break through the teacher to teach the students to learn, and curriculum evaluation pressure will have a negative incentive for interest led learning. The mobile phone application in English learning can improve the negative effect by the integral system, membership model, with a back word software as an example, every user needs to set the amount of memory, memory and mind through the daily detection of the day after the goal, and after the completion of the user can choose to share to my circle of friends, micro-blog WeChat and in the space, so the user visual learning effect to meet the dual concern and fun to achieve goals. Reasonable design is the key to learning content, but it is based on the network platform, can be designed 
according to the level of teaching content, the students according to their actual English level, reasonable choice of teaching content, to improve their English level. At the same time, after many days of punch, the user will get a series of incentives provided by the software, some software may even provide discount movie tickets and other activities, learning English and other recreational activities linked to the user. In College English teaching, encourage students to use knowledge and problem of mobile terminals and solutions in the teaching of learning, to develop students' horizons, expand knowledge of students, to better meet the needs of the society for applied talents. In the final test, teachers should change the traditional examination mode to increase the usual assessment scores in a modest degree.

\section{Conclusion}

In the era of mobile fragmentation, students' learning is no longer confined to the formal classroom teaching. It occurs in a wide range of real social environment. As an important new method, the study of mobile fragmentation will have a variety of effects on traditional college English teaching. Teachers should actively innovate teaching methods to meet the challenges brought by mobile fragmentation learning.

\section{References}

[1] Tian Lan, The cultivation of teachers' and students' subjective cognitive thinking in professional English teaching [J]. Journal of Central South University (Social Science), 2014, 20(4): 249-253.

[2] Zhang Dan, Application of WeChat in the Second Classroom of College English Teaching [J]. Overseas English, 2015(10): 39-40.

[3] Xu Xianqiao, Fragmentation Learning of College English from the Perspective of Big Data [J]. Journal of Bengbu University, 2016, 5(1): 95-98.

[4] Zuo Baoxia, A Practical Research on Advanced English Flipped Class Mode Based on WeChat under Environment of Mobile Learning [J]. Value Engineering, 2016(12): 212-213. 